\title{
Distribution of Fusarium mycotoxins in wheat milling process
}

\author{
Casiane Salete Tibola*, José Mauricio Cunha Fernandes, Eliana Maria Guarienti, \\ Marcio Nicolau
}

Embrapa Wheat, Rodovia BR-285, Km 294 - C.P. 3081, Passo Fundo, RS, 99001-970, Brazil

\section{A R T I C L E I N F O}

\section{Article history:}

Received 5 December 2014

Received in revised form

13 January 2015

Accepted 14 January 2015

Available online 24 January 2015

\section{Keywords:}

Deoxynivalenol

Ergosterol

Wheat

Milling process

\begin{abstract}
A B S T R A C T
Fusarium head blight (FHB) is a fungal disease that affects cereals and is capable of producing mycotoxins, creating health concerns. In southern Brazil, FHB of wheat is caused by the Fusarium graminearum species complex that produces mainly deoxynivalenol (DON) and zearalenone (ZON) mycotoxins. There is a need for research-based information on how different contamination levels affect these mycotoxins' distribution in the milling process. The objective of this study was to analyze the Fusarium mycotoxin distribution within each milled fraction, extracted from wheat lots artificially contaminated with a crescent gradient of mycotoxins. Wheat samples produced in 2013 season in Southern Brazil region were obtained from plots of breeding program. The wheat samples were artificially contaminated with residues of cleaning and pre-cleaning process, including light and shriveled grains, obtained from a Fusarium nursery screening plot. Pilot-scale milled wheat fractions were collected, comprising finished flour and bran. The Fusarium mycotoxin content was determined by chromatography (UHPLC-MS/MS). The results obtained show that DON presented exponential growth relative to the initial levels of mycotoxin in wheat milled fractions (finished flour and bran). The DON concentration was significativelly higher in bran, when compared with milled wheat and finished flour, in the DON levels lower than $1000 \mu \mathrm{g} \mathrm{kg}$ The finished flour presented lower DON levels when compared with milled wheat, but this reduction was inadequate, to meet the current regulation limits for food.
\end{abstract}

(C) 2015 Elsevier Ltd. All rights reserved.

\section{Introduction}

Wheat is mainly used in human consumption, thus most of it is subject to milling. The main Brazilian wheat growing area, where more than 90 percent of it is grown, is located in the South. This region lies from Rio Grande do Sul to Paraná (latitude $28^{\circ} \mathrm{S}$ to $23^{\circ} \mathrm{S}$ ) and the main limiting factor for wheat production is the excess of humidity, which favors fungal diseases outbreaks. In particular, Fusarium Head Blight (FHB) is influenced by warm temperature and rainy days during the flowering time. Apart from losses in grain yield and reductions in baking and seed quality, the major concern due to FHB is contamination with toxic fungal secondary metabolites, known as mycotoxins (Buerstmayr, Ban, \& Anderson, 2009). Mycotoxins are secondary metabolites produced naturally by filamentous fungi, which are considered toxic substances when present in food for humans and feed for animals (Rocha, Freire, Maia, Guedes, \& Rondina, 2014). Fusarium graminearum sensu stricto

\footnotetext{
* Corresponding author. Tel.: +55 5433165941 .

E-mail address: casiane.tibola@embrapa.br (C.S. Tibola).
}

(Fgss) is the predominant species in Brazil, detected in 90\% of isolates, and is potentially a deoxynivalenol (DON) producer, according to molecular methods that characterizes genes involved in the synthesis of trichothecenes (Del Ponte, Tessmann, Spolti, Kuhnem, \& Silva, 2013). FHB mycotoxins, mainly deoxynivalenol, can bind to the $60 \mathrm{~S}$ ribosomal subunit of eukaryotes, resulting in protein synthesis inhibition and apoptosis (Terzi, Tumino, Stanca, \& Morcia, 2013).

In order to protect consumers from mycotoxicosis, many countries established maximum allowed levels for the most prevalent Fusarium mycotoxins in cereals and cereal by-products. The European Union has established the most comprehensive regulations for food and cereal safety, to facilitate world trade and protect consumer health (Cheli, Battaglia, Gallo, \& Dell'Orto, 2014). In Brazil, the mycotoxin regulation is progressively more restrictive; in 2012 the upper limits established for whole wheat and white flour were $2000 \mu \mathrm{g} \mathrm{kg}^{-1}$ and $1750 \mu \mathrm{g} \mathrm{kg}{ }^{-1}$, respectively (ANVISA, 2011). These levels will be progressively reduced, and in 2017, they will be $1000 \mu \mathrm{g} \mathrm{kg}^{-1}$ and $750 \mu \mathrm{g} \mathrm{kg}^{-1}$ (ANVISA, 2013). The unprocessed wheat grain upper limit will be $3000 \mu \mathrm{g} \mathrm{kg}^{-1}$ in 2017 (ANVISA, 2013). The Brazilian regulations also limited zearalenone 


\begin{tabular}{|ll|}
\hline \multicolumn{2}{|l|}{ Nomenclature } \\
DON $\quad$ Deoxynivalenol \\
3-ADON & DON acetylated derivatives \\
15-ADONDON acetylated derivatives \\
ZON & Zearalenone \\
NIV & Nivalenol \\
FHB & Fusarium Head Blight \\
\hline
\end{tabular}

(ZON) levels in cereals and by-products; in 2012, the upper levels for whole wheat and wheat flour were $400 \mu \mathrm{g} \mathrm{kg} \mathrm{kg}^{-1}$ and $200 \mu \mathrm{g} \mathrm{kg}^{-1}$, respectively (ANVISA, 2011). Both levels will be halved by 2017 (ANVISA, 2013). Currently, no regulation limits have been established for animal feed in Brazil.

In the post-harvest stage, the cleaning, aeration, debranning and milling procedures certainly have an influence in the distribution of mycotoxins in wheat fractions. In the milling process there is no mycotoxin reduction, although mycotoxin concentrations may be redistributed and concentrate according to the milling fractions. Mycotoxins tend to be concentrated in outer fractions intended for animal feed (bran, flour shorts screenings and middlings) and lower in inner fractions intended for human consumption (flour or semolina) (Cheli, Pinotti, Rossi, \& Dell'Orto, 2013). However, this mycotoxin distribution pattern is highly variable in wheat milled fractions. The main factors for these conflicting results may be due to type of mycotoxin (hydrophilic/hydrophobic), the genotype, the level and time of fungal contamination, and the milling methodology (Cheli et al., 2013).

Previous studies showed that the tricothecenes (DON and NIV) had identical patterns among milling fractions distribution, while the transfers ratios of ZON had different features (Zheng et al., 2014). In contrast to the trichothecenes, which are soluble in water, zearalenone is hydrophobic (soluble in organic solvents). Differences in the retention of DON and ZON in patent flour may be derived from the water content within the grain. The endosperm is characterized by high moisture content (over 35\%), thus the DON and other trichothecenes, which are hydrophilic, presented higher recovery in patent flour $\left(670 \mu \mathrm{g} \mathrm{kg}^{-1}\right)$, when compared with ZON $\left(160 \mu \mathrm{g} \mathrm{kg}^{-1}\right)$ in norin 61 Japanese cultivar (Zheng et al., 2014). Recently, Cheli et al. (2013) presented a comprehensive review about the effects of milling on mycotoxin distribution in wheat; the overall reduction of DON content commonly ranged from 50 to $70 \%$ in semolina, when compared with initial unprocessed wheat. On the other hand, in bran, mainly used for animal feed, the increase of DON levels ranged from 150 to $340 \%$.

Therefore, the understanding of the effects of the milling process in the mycotoxin distribution is a worldwide topic of interest, due to the high economic and health impact. Considering the levels indicated for unprocessed cereals, sometimes it may not warranty the limits proposed for cereal-derived products (Cheli et al., 2013). In Brazil, the discrepancy between the acceptable levels of mycotoxin in unprocessed cereals and by-products resulted in the extension of 2012 levels till 2017, by the government control agencies (ANVISA, 2013). So, it is a priority to identify the effects of the wheat milling process on mycotoxin repartitioning, to subsidize the wheat productive chain and to meet the upcoming legislation requirements. Moreover, the results of the mycotoxin distribution in the milling stream byproducts, usually intended for animal feed, may also represent a useful support in the perspective of maximum limits settings in the future. The objective of this study was to evaluate the influence of the wheat milling process on Fusarium mycotoxin content, using wheat lots artificially contaminated with a crescent gradient of mycotoxins.

\section{Methodology}

\subsection{Sampling characterization}

Wheat samples from different cultivars, harvested in 2013 crop season from Southern Brazil, were used. The samples were obtained from field yield trials of Embrapa's breeding program. The geographical distribution included mainly Rio Grande do Sul State, and one sample from Santa Catarina state, both located in Southern Brazil. The major Fusarium disease outbreaks in the country are concentrated in that region. Nevertheless, in the 2013 season the natural levels of DON content in the selected set of samples, were below $400 \mu \mathrm{g} \mathrm{kg}^{-1}$ (data no shown). Therefore, these wheat samples were artificially contaminated with residues of the cleaning and pre-cleaning process, including light and shriveled grains, obtained from different wheat cultivars susceptible to FHB. These FHB-damaged kernels were obtained from wheat produced under field conditions favorable to fungal growth (nursery). In FHB nursery, mist irrigation was provided from flowering to grain filling stage, in order to favor disease development. So, the mycotoxin content of these residues was obtained by ELISA (AgraQuant ${ }^{\mathbb{B}}$ Deoxynivalenol), to establish the contamination gradient and the amount of residues necessary for the artificial contamination.

In the artificial contamination, a contamination gradient was obtained with six different levels of deoxynivalenol, ranging from $<200$ to $>3000 \mu \mathrm{g} \mathrm{kg}^{-1}$, with $6000 \mathrm{~g}$ each. These levels of mycotoxins were defined based on human and animal mycotoxin regulations worldwide. Each sample was thoroughly mixed before six sub-samples were collected to obtain a laboratory sample.

The moisture and protein contents were determined by Near Infrared Reflectance Spectroscopy (NIR instrument FOSS XDS RCA, Hoganas, Sweden), in all samples. The six wheat lots showed these chemical caracteristics, i.e., protein ranging from $12.3 \%$ to $13.5 \%$ and moisture content ranging from $14.6 \%$ to $15.8 \%$. The yield of flour obtained from wheat in the milling process were $44.7 \%$, $43.9 \%, 42.0 \%, 43.2 \%, 42.6 \%$ and $40.1 \%$, respectively, from level 1 to level 6 of initial contamination.

\subsection{Milling procedures}

The samples were milled according to the mycotoxin concentration, from low to high content, to minimize cross-contamination in the milling process. Cleaned wheat $(1000 \mathrm{~g})$ was milled in the Laboratory Mill $3100^{\circledR}$ (Perten, Sweden), to obtain the milled whole wheat fraction. The same set of samples, composed of $5000 \mathrm{~g}$, were conditioned to $14 \%$ moisture content (weight and moisture content measured) and milled using a pilot-scale mill Quadrumat Senior ${ }^{\mathbb{B}}$ (Brabender, Germany), with a standard setting for hard wheat (AACC, 2000). This mill simulates the industrial milling process, and recovers approximately $98 \%$ of wheat fractions. The mill produced the following fractions: one breaking flour and one reduction flour and two outer layer fractions (bran and shorts). All milling fractions were kept at $8^{\circ} \mathrm{C}$ prior to use.

The following fractions were collect for mycotoxin analysis: finished flour (reduction and break flour) and bran (shorts and bran). Finished flour (patent flour or semolina) was obtained directly from the mill and is the sole component of commercial flour. The shorts and bran were mixed to obtain a single sample. Shorts, is a mixture of germ and fine bran, separated from reduction flour after reduction rollers. Finally, bran, the outer layers of wheat kernel, is coarse, separated from break flour after the break rollers and used mainly to animal feed. 
Each fraction was weighted and mixed, before the separation of $200 \mathrm{~g}$ for mycotoxin analysis. All the collected set of samples were sent for mycotoxin quantification at reference laboratory (Samitec, Santa Maria/RS).

\subsection{Mycotoxin and ergosterol analysis}

DON and its acetylated derivatives (15-ADON and 3-ADON), nivalenol and ZON contents were determined by ultra highperformance liquid chromatography-tandem with triple quadrupole mass spectrometry (UHPLC-MS/MS). The extraction, clarification and derivatization methodology is fully automatized, developed and validated in house, using the method described in Varga et al. (2012). The laboratory presents the following limits of quantification and recovery: for DON $200 \mu \mathrm{g} \mathrm{kg}^{-1}$ and $80 \%$; for $15-$ ADON, 3-ADON and NIV $100 \mu \mathrm{g} \mathrm{kg}^{-1}$ and $91 \%, 87 \%$ and $74 \%$, respectively; finally, for ZON, the limits of quantification/recovery were $20 \mu \mathrm{g} \mathrm{kg}^{-1} / 85 \%$.

Ergosterol, a fungal marker was analyzed, to elucidate the relationship between toxin accumulation and fungal dispersion in wheat layers. Ergosterol was measured by high-performance liquid chromatography (HPLC), as described in Moraes et al. (2003). The limits of quantification and recovery for ergosterol were $110 \mu \mathrm{g} \mathrm{kg}^{-1}$ and $99.6 \%$, respectively.

\subsection{Statistical analysis}

The samples within the six initial levels of DON, were homogenized and quadruplicates $(n=4)$ were collected for mycotoxin analysis in milled wheat and in milled fractions.

Lme4 package developed by Bates, Maechler, Bolker, and Walker (2014), was used to fit a linear mixed effects model to the data. Prior the fitting process, the raw data were linearized using a logarithmic transformation. Then a varying-intercept model was fitted to data corresponding to each stratum represented by type variable. A Likelihood Ratio Test (LRT) procedure was used for model selection. R Code Team Software (2014) was used for analyzing the data.

Results regarding average DON in unprocessed wheat and in milling fractions, for each mycotoxin level, were reported as the Mean \pm Standard Deviation (SD). The parameter Distribution Factor, previously reported in Cheli et al. (2010), was adopted to express the overall reduction or increase in DON content in each milled fraction compared to their respective contents measured in milled wheat. This parameter was expressed as a percentage and it was calculated as the ratio between mycotoxin content in processed fractions and its content in unprocessed whole wheat.

\section{Results}

\subsection{Ergosterol content}

Ergosterol is a metabolite used as an indicator of fungal colonization in grains. The distribution of ergosterol in the wheat milled

Table 1

Mean of ergosterol $\left(\mu \mathrm{g} \mathrm{kg}^{-1}\right)$, in milled wheat and in milling fractions.

\begin{tabular}{lllr}
\hline $\begin{array}{l}\text { Levels of DON } \\
\left(\mu \mathrm{gg}^{-1}\right)\end{array}$ & $\begin{array}{l}\text { Milled wheat } \\
\left(\mu \mathrm{g} \mathrm{kg}^{-1}\right)\end{array}$ & $\begin{array}{l}\text { Finished flour } \\
\left(\mu \mathrm{g} \mathrm{kg}^{-1}\right)\end{array}$ & \multicolumn{1}{c}{$\begin{array}{l}\text { Bran } \\
\left(\mu \mathrm{g} \mathrm{kg}^{-1}\right)\end{array}$} \\
\hline (1) $0-200$ & 664.4 & $\mathrm{ND}^{\mathrm{a}}$ & 1596.0 \\
(2) $201-500$ & 3322.3 & 748.7 & 3959.6 \\
(3) $501-1000$ & 3239.0 & 578.9 & 3463.3 \\
(4) $1001-1500$ & 2101.1 & 745.2 & 5951.7 \\
(5) $1501-3000$ & 4649.2 & 837.1 & 9687.4 \\
(6) $>3000$ & 6939.5 & 2864.0 & $10,306.0$ \\
\hline
\end{tabular}

${ }^{\mathrm{a}} \mathrm{ND}$ : Below the limit of quantification $\left(<110 \mu \mathrm{g} \mathrm{kg}^{-1}\right)$. fractions was similar to deoxynivalenol. The concentration of ergosterol was always lower in finished flour and higher in bran, indicating that most of the fungi were retained in the outer layers of grain in all levels of mycotoxins (Table 1 ).

\subsection{Deoxynivalenol content}

The DON content in wheat milled fractions (finished flour and bran), increased exponentially in relation to the initial levels of mycotoxin in the milled wheat (Fig. 1).

In the lower gradient levels, from $<200$ to $1000 \mu \mathrm{g} \mathrm{kg}^{-1}$, the DON concentration is significativelly different in bran compared with milled wheat and finished flour. When the initial toxin concentration gradient increased, all milled fractions increased similarly. Thus, the higher level of DON observed in bran $\left(8000 \mu \mathrm{g} \mathrm{kg}^{-1}\right)$, was not significantly different from milled wheat and finished flour $\left(6000 \mu \mathrm{g} \mathrm{kg}^{-1}\right)$.

The mean DON concentrations in cleaned milled wheat and wheat milled fractions are presented in Table 2. DON was present in all samples, except level $1\left(0-200 \mu \mathrm{g} \mathrm{kg}^{-1}\right)$. The DON content in samples 2 through 6 ranged from $<200$ to $6150 \mu \mathrm{g} \mathrm{kg}^{-1}$ in milled wheat. DON contamination in finished flour ranged from $<200$ to $5830 \mu \mathrm{g} \mathrm{kg}^{-1}$. The maximum DON concentration was observed in the bran, regardless of initial contamination level (Table 2).

Overall, using the five contrasting levels of mycotoxins (from $>200$ to $>3000 \mu \mathrm{g} \mathrm{kg}^{-1}$ ), DON concentrations in finished flour were reduced by $19 \%$, although in bran it increased by $125 \%$, when compared with milled wheat using pilot-scale milling process (Table 2). The distribution patterns among all fractions were variable, particularly for finished flour, where the retention of DON was reduced by approximately $43 \%$ in level $2\left(201-500 \mu \mathrm{g} \mathrm{kg}^{-1}\right)$ and only $11 \%$ in the highest level of contamination $\left(>3000 \mu \mathrm{g} \mathrm{kg}^{-1}\right)$, when compared with milled wheat.

\subsection{Zearalenone, nivalenol and DON acetylates levels}

ZON was detected only in the two higher levels of initial contamination of mycotoxins (Table 3 ). In the finished flour fraction, $\mathrm{ZON}$ was not detected in any analyzed sample.

The DON acetylated derivatives (15-ADON and 3-ADON) and nivalenol were not detected in any sample (data no shown).

\section{Discussion}

The higher levels of mycotoxin were more likely to occur due to the fungal growth in the inner grain layers, promoted by the ideal conditions in the FHB nursery, than mycotoxin diffusion among grain layers (Table 1). Our results are in agreement with other studies conducted by Young, Fulcher, Hayhoe, Scott, and Dexter (1984), Trigo-Stocki (2002) and Pinson-Gadais et al. (2007), which indicated that the effectiveness of the milling process, in reducing the level of DON in semolina, depends on the extent of the fungi penetration in the wheat kernels. According to Young et al. (1984), the mycotoxin is produced at the site of fungal growth, rather than transported from the kernel surface to the interior. A more recent study indicated that the DON concentration in flour fractions was equivalent to that of the milled wheat, with a lower concentration in outer layers (bran), in the wheat from a season characterized by high pre-harvest rainfall, which resulted in movement of DON to inner layers due to the DON highly solubility in water (Edwards et al., 2011). In our study, the DON and ZON distribution in wheat fractions also resulted in movement of DON inside the grains, although, there was no significant distribution of ZON within wheat inner layers. Although, ZON were quantifiable only in a small number of samples. A study conducted by Pinson-Gadais et al. 

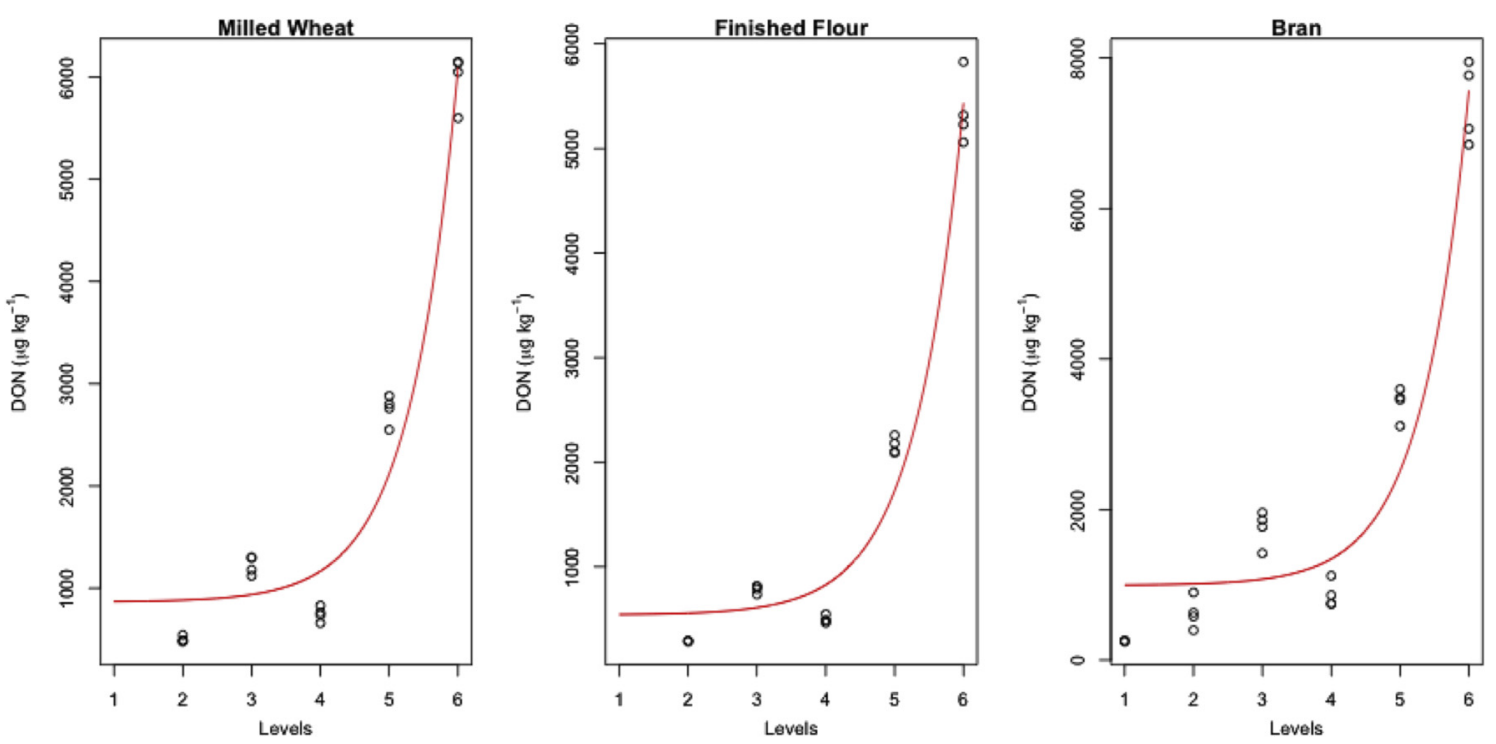

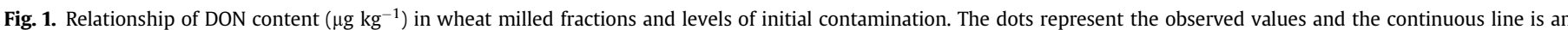
exponential curve fitted to the data.

(2007), reported the penetration of toxigenic Fusarium fungi into the interior of durum wheat kernel and indicated that none of the tissue structures within the wheat kernel acted as an effective barrier to fungal invasion. Moreover, after inoculation by toxigenic Fusarium strains, semolina was shown to allow high yields of trichothecenes, while bran was demonstrated to contain biochemical inhibitors able to significantly reduce trichothecene production.

Table 2

Average DON levels and distribution factors in wheat and milling fractions.

\begin{tabular}{|c|c|c|c|}
\hline $\begin{array}{l}\text { Levels of DON } \\
\left(\mu \mathrm{kg}^{-1}\right)\end{array}$ & Fractions & $\begin{array}{l}\text { Mean } \pm \text { standard deviation of } \\
\text { DON }\left(\mu \mathrm{gg}^{-1}\right)\end{array}$ & $\begin{array}{l}\text { Distribution } \\
\text { factor }^{\mathrm{a}}(\%)\end{array}$ \\
\hline \multirow[t]{3}{*}{ (1) $0-200$} & $\begin{array}{l}\text { Milled } \\
\text { wheat }\end{array}$ & $\mathrm{ND}^{\mathrm{b}}$ & - \\
\hline & $\begin{array}{l}\text { Finished } \\
\text { flour }\end{array}$ & ND & - \\
\hline & Bran & $252.67 \pm 7.09$ & - \\
\hline \multirow[t]{3}{*}{ (2) 201-500 } & $\begin{array}{l}\text { Milled } \\
\text { wheat }\end{array}$ & $498.75 \pm 29.30$ & 100.00 \\
\hline & $\begin{array}{l}\text { Finished } \\
\text { flour }\end{array}$ & $288.67 \pm 4.16$ & 57.87 \\
\hline & Bran & $626.25 \pm 207.00$ & 125.56 \\
\hline \multirow[t]{3}{*}{ (3) $501-1000$} & $\begin{array}{l}\text { Milled } \\
\text { wheat }\end{array}$ & $746.50 \pm 70.71$ & 100.00 \\
\hline & $\begin{array}{l}\text { Finished } \\
\text { flour }\end{array}$ & $495.75 \pm 36.10$ & 66.40 \\
\hline & Bran & $870.00 \pm 175.21$ & 116.54 \\
\hline \multirow[t]{3}{*}{ (4) $1001-1500$} & $\begin{array}{l}\text { Milled } \\
\text { wheat }\end{array}$ & $1225.00 \pm 90.00$ & 100.00 \\
\hline & $\begin{array}{l}\text { Finished } \\
\text { flour }\end{array}$ & $787.00 \pm 36.08$ & 64.24 \\
\hline & Bran & $1752.50 \pm 234.8$ & 143.06 \\
\hline \multirow[t]{3}{*}{ (5) 1501-3000 } & $\begin{array}{l}\text { Milled } \\
\text { wheat }\end{array}$ & $2747.50 \pm 140.80$ & 100.00 \\
\hline & $\begin{array}{l}\text { Finished } \\
\text { flour }\end{array}$ & $2157.50 \pm 79.32$ & 78.525 \\
\hline & Bran & $3415.00 \pm 212.05$ & 124.29 \\
\hline \multirow[t]{3}{*}{ (6) $>3000$} & $\begin{array}{l}\text { Milled } \\
\text { wheat }\end{array}$ & $5985.00 \pm 260.57$ & 100.00 \\
\hline & $\begin{array}{l}\text { Finished } \\
\text { flour }\end{array}$ & $5360.00 \pm 331.36$ & 89.55 \\
\hline & Bran & $7407.50 \pm 534.56$ & 123.76 \\
\hline
\end{tabular}

a Distribution factor: percentage of overall reduction or increase in DON content for each milling fraction, in comparison with initial level in unprocessed wheat.

b ND: Below the limit of quantification $\left(<200 \mu \mathrm{g} \mathrm{kg}^{-1}\right)$.
Different from our results, Thammawong et al. (2011) reported that DON and NIV distributions were different from ergosterol, indicating that the diffusion of toxins inside the grain is independent of fungal biomass in wheat artificially inoculated with Fusarium graminearum. We considered that this difference might be due to the heavily Fusarium-damaged kernels used in this study, where the artificial contamination was performed by mixing Fusarium damaged wheat kernels from FHB susceptible cultivars produced in the Fusarium nursery (highly favorable environment).

Edwards et al. (2011) stated that the proportion of DON in flour increased as the concentration of DON in original wheat lot increased. In our study, DON content was significantly higher in bran, when compared to milled wheat and finished flour, in the lower contamination levels $\left(<200-1000 \mu \mathrm{g} \mathrm{kg}^{-1}\right)$. However, similar levels of DON among finished flour fractions and whole milled wheat were observed in all contamination levels, indicating that toxins were not removed by the milling process. These results are in agreement with previous studies, that used heavily Fusariuminfected wheat grains. Thammawong et al. (2011) examined the milling effect in wheat with low, medium and high DON contamination levels. In the medium $\left(900 \mu \mathrm{g} \mathrm{kg}^{-1}\right)$ and higher levels $\left(5270 \mu \mathrm{g} \mathrm{kg}^{-1}\right)$ DON accumulation in patent flour was similar to the levels obtained in the original grains. According to their results,

Table 3

Average ZON levels and distribution factors in wheat and milling fractions

\begin{tabular}{llll}
\hline $\begin{array}{l}\text { Levels of DON } \\
\left(\mu \mathrm{kg}^{-1}\right)\end{array}$ & Fractions & $\begin{array}{l}\text { Mean } \pm \text { standard deviation of } \\
\mathrm{ZON}\left(\mu \mathrm{kg}^{-1}\right)\end{array}$ & $\begin{array}{l}\text { Distribution } \\
\text { factor }^{\mathrm{a}}(\%)\end{array}$ \\
\hline (5) $1501-3000$ & $\begin{array}{l}\text { Milled } \\
\text { wheat }\end{array}$ & $27.55 \pm 1.84$ & 100.00 \\
& $\begin{array}{l}\text { Finished } \\
\text { flour }\end{array}$ & $\mathrm{ND}^{\mathrm{b}}$ & \\
& Bran & $62.60 \pm 42.80$ & 227.22 \\
(6) $>3000$ & Milled & $38.65 \pm 6.52$ & 100.00 \\
& wheat & & \\
& Finished & $\mathrm{ND}$ & 158.21 \\
& flour & & \\
& Bran & $61.15 \pm 158.21$ & \\
\hline
\end{tabular}

a Distribution factor: percentage of overall reduction or increase in ZON conten for each milling fraction in comparison with initial level in unprocessed wheat.

b ND: Below the limit of quantification $\left(<20 \mu \mathrm{g} \mathrm{kg}^{-1}\right)$. 
only the bran differed among fractions and presented significantly higher DON levels.

Other studies, with lower levels of initial mycotoxin contamination, reported higher DON reduction in semolina during the milling process. Cheli et al. (2010), reported that DON concentrations in semolina reduced by $60 \%$, although in shorts (middling) it increased by $152 \%$, when compared with unprocessed wheat (68.58 $\mu \mathrm{g} \mathrm{kg}^{-1}$ ), using conventional milling. The relative concentration of DON in semolina declined $40.7 \%$ and increased by $162.4 \%$ in bran, in comparison to the initial levels obtained in whole milled wheat (1890 $\mu \mathrm{g} \mathrm{kg}^{-1}$ ) (Zheng et al., 2014). Similar to our findings, Thammawong et al. (2011) reported that DON concentration decreased $11.2 \%$ in patent flour and increased $137 \%$ in bran, when compared with milled wheat, in the higher level of initial contamination (5270 $\mu \mathrm{g} \mathrm{kg}^{-1}$ ). Zhang and Wang (2014) reported contrasting results showing DON reductions of $79-90 \%$ in the finished flour, when compared with milled wheat, with initial levels of contamination ranging from 4680 to $36,719 \mu \mathrm{g} \mathrm{kg}^{-1}$. These great differences in results might be accounted by the cultivar effect and the degree of fungal penetration in wheat kernel (PinsonGadais et al., 2007; Young et al., 1984; Zhang \& Wang, 2014). Fungal colonization limited to outer layers results in higher toxins concentration in the grain surface. To summarize, all studies reported similar trends, with more toxins being accumulated in the surface of wheat kernels and the main sources of difference in mycotoxin distribution were: cultivar effect, degree and time of fungal infection, the weather conditions and the milling process.

According to our study, when DON contaminated unprocessed wheat enters the milling process with maximum level (3000 $\mu \mathrm{g} \mathrm{kg}^{-1}$ ), there are concerns raised in flour production. In both maximum contamination levels 5 and 6 (1501-3000 and $>3000 \mu \mathrm{g} \mathrm{kg}^{-1}$ ), the content of DON in finished flour was higher than the upcoming upper limit settled at $750 \mu \mathrm{g} \mathrm{kg}$, for 2017 (ANVISA, 2013). The DON content in wheat milled fractions (finished flour and bran), presented an exponential growth pattern, thus requiring lower initial contamination in raw grain, to guarantee food safety in by-products. In turn, level 4 was the closest to the levels foreseen in Brazilian mycotoxin regulations in 2017; the mean of DON in milled wheat was $1225 \mu \mathrm{g} \mathrm{kg}^{-1}$ and in the finished flour was $787 \mu \mathrm{g} \mathrm{kg}^{-1}$. Below this level, would be the maximum DON content tolerable, to meet the upcoming regulation criteria.

More studies are necessary to evaluate the seasonal climate variation, which is the major factor to promote Fusarium outbreaks. Further investigations, with broad samples set under natural contamination conditions, will contribute to understanding the fate of these contaminants in the primary processing.

\section{Conclusion}

We conducted a study concerning the impact of milling processes on the Fusarium mycotoxin content in wheat artificially contaminated and displaying contrasting levels of mycotoxins $\left(<200\right.$ to $\left.>3000 \mu \mathrm{g} \mathrm{kg} \mathrm{kg}^{-1}\right)$. In the lower gradient levels $\left(<1000 \mu \mathrm{g} \mathrm{kg}^{-1}\right)$, DON concentration is significativelly different in bran compared with milled wheat and finished flour. The milling process cannot be solely used as an effective tool for DON reduction in the finished flour, especially in the higher contaminated wheat lots. The mycotoxin concentration, in the inner grain layers, must be due to the fungal growth within the grain, rather than the toxin diffusion.

\section{Acknowledgments}

We are grateful to the financial support for this study provided by Brazilian Agricultural Research Corporation (Embrapa). The authors wish to thank Rogerio Delanora (Embrapa Trigo, Passo Fundo, Brazil), for mycotoxin analysis support.

\section{References}

AACC International. (2000). Approved methods of analysis (10th ed.). St. Paul: AACC International (Method 26-10A). Experimental milling: introduction, equipment, sample preparation, and tempering. Approved November 8, 2000.

ANVISA. (2011). RDC Resolution n. 7, February 18, 2011. Technical regulation on tolerable maximum levels (LMT) for mycotoxins in food. Brasília, DF: ANVISA.

ANVISA. (2013). RDC Resolution n. 59, December 26, 2013. Extension of time limits established in the RDC n.7. Brasília, DF: ANVISA.

Bates, D., Maechler, M., Bolker, B., \& Walker, S. (2014). Ime4: Linear mixed-effects models using Eigen and S4. $R$ package version 1.1-7. http://CRAN.R-project.org/ package =lme4 Accessed on: Nov. 2014.

Buerstmayr, H., Ban, T., \& Anderson, J. A. (2009). OTL mapping and marker-assisted selection for Fusarium head blight resistance in wheat: a review. Plant Breeding, $128,1-26$.

Cheli, F., Battaglia, D., Gallo, R., \& Dell'Orto, V. (2014). EU legislation on cereal safety: an update with a focus on mycotoxins. Food Control, 37, 315-325.

Cheli, F., Campagnoli, A., Ventura, V., Brera, C., Berdini, C., Palmaccio, E., et al. (2010). Effects of industrial processing on the distributions of deoxynivalenol, cadmium and lead in durum wheat milling fractions. LWT - Food Science and Technology, 43, 1050-1057.

Cheli, F., Pinotti, L., Rossi, L., \& Dell'Orto, V. (2013). Effect of milling procedures on mycotoxin distribution in wheat fractions: a review. LWT. Food Science and Technology, 54(2), 307-314.

Del Ponte, E. M., Tessmann, D. J., Spolti, P., Kuhnem, P. R., \& Silva, C. N. (2013). Species identification, genetic diversity and phenotypic variation studies on the Fusarium graminearum complex populations from Brazil. In T. M. Alconada Magliano, \& S. N. Chulze (Eds.), Fusarium head blight in Latin America (pp. 15-29). Netherlands: Springer.

Edwards, S. G., Dickin, E. T., MacDonald, S., Buttler, D., Hazel, C. M., Patel, S., et al. (2011). Distribution of Fusarium mycotoxins in UK wheat mill fractions. Food Additives and Contaminants, 28(12), 1694-1704.

Moraes, R. J. Q., Almeida, C. A. A., Dilkin, P., Kowalski, C. H., Mürmann, L., \& Mallmann, C. A. (2003). Doses of ergosterol as fungal contamination indicator in stored corn. Arquivos do Instituto Biológico, 70(4), 483-489.

Pinson-Gadais, L., Barreau, C., Chaurand, M., Gregoire, S., Monmarson, M., \& Richard-Forget, F. (2007). Distribution of toxigenic Fusarium spp. and mycotoxin production in milling fractions of durum wheat. Food Additives \& Contaminants, $24,53-62$

$\mathrm{R}$ Core Team. (2014). R: A language and environment for statistical computing. $\mathrm{R}$ Foundation for Statistical Computing. http://www.R-project.org Accessed on: Nov. 2014.

Rocha, M. E. B. da, Freire, F.da C. O., Maia, F. E. F., Guedes, M. I. F., \& Rondina, D. (2014). Mycotoxins and their effects on human and animal health. Food Control, 36(1), 159-165.

Terzi, V., Tumino, G., Stanca, A. M., \& Morcia, C. (2013). Reducing the incidence of cereal head infection and mycotoxins in small grain cereal species. Journal of Cereal Science, 59(3), 284-293.

Thammawong, M., Okadome, H., Shiina, T., Nakagawa, H., Nagashima, H. Nakajima, T., et al. (2011). Distinct distribution of deoxynivalenol, nivalenol, and ergosterol in Fusarium-infected Japanese soft red winter wheat milling fractions. Mycopathologia, 172, 323-330.

Trigo-Stocki, D. M. (2002). Effect of processing on deoxynivalenol and other trichothecenes. In J. W. DeVries, M. W. Trucksess, \& L. S. Jackson (Eds.), Mycotoxins and food safety (pp. 181-188). New York: Kluwer Academic/Plenum Publishers.

Varga, E., Glauner, T., Köppen, R., Mayer, K., Sulyok, M., Schuhmacher, R., et al. (2012). Stable isotope dilution assay for the accurate determination of mycotoxins in maize by UHPLC-MS/MS. Analytical and Bioanalytical Chemistry, 402(9), 2675-2686.

Young, J. C., Fulcher, R. G., Hayhoe, J. H., Scott, P. M., \& Dexter, J. E. (1984). Effect of milling and baking on deoxynivalenol (vomitoxin) content of eastern Canadian wheats. Journal of Agriculture and Food Chemistry, 32, 659-664.

Zhang, H., \& Wang, B. (2014). Fate of deoxynivalenol and deoxynivalenol-3glucoside during wheat milling and Chinese steamed bread processing. Food Control, 44, 86-91.

Zheng, Y., Hossen, S. M., Sago, Y., Yoshida, M., Nakagawa, H., Nagashima, H., et al. (2014). Effect of milling on the content of deoxynivalenol, nivalenol, and zearalenone in Japanese wheat. Food Control, 40, 193-197. 